\title{
Crash Analysis on the Automotive Vehicle Bumper
}

\author{
Raj Kumar G, Balasubramaniyam S, Senthil Kumar M, Vijayanandh R, Raj Kumar R, Varun S
}

\begin{abstract}
In this article deals the crash investigation of Bumper for different materials using ANSYS Workbench. Bumper is a vital parameter which is used as safety protection for passengers from accidents by means of impact energy absorption from collision environment. The ultimate focus of this work is material optimization for Bumper by performing impact analysis with the help of ANSYS. The entire analysis process comprises of two stages, which are conceptual design of Bumper and preparation of Bumper for numerical analysis. The optimization of this work is based on structural parametric results, in which total deformation, equivalent stress induced are primarily involved. . The reference component's modeling process is completed by means of CATIA, and then the impact analysis is carried by ANSYS Workbench 16.2, in which the materials used for bumper are Steel and Glass fiber based composite with the constant boundary conditions [speed $=13.3 \mathrm{~m}$ sec-1]. Finally suitable material is finalized for car bumper.
\end{abstract}

Keywords: Crash, Composite Materials, Comparison, Deflection, Stress.

\section{INTRODUCTION}

A bumper is a productive element made up of well known materials such as aluminum, plastic, and steel, etc., which is locating on both the ends of the automotive vehicle. The prime aim of the bumper is to provide the safety and security to the passengers by absorbing the impact energy when low speed collision occurs in the car. The existing bumper has capable to withstand high amount load with more weight. More weight drastically reduces the fuel efficiency and thereby affects the efficiency of the car. Hence the reduction in the weight with high withstanding capability is the fundamental need of the future vehicle's bumper. Generally Steel is the best material for bumper to absorbing the impact load but the additional problem associates with steel is more weight so integrational effect is mandatory in bumper. Therefore Composite is most suitable for bumper, in which glass fiber/epoxy resin based composites have the capability to withstand high amount of load. The bending moment equation primarily supports the estimation of bumper's dimensions such as thickness, length, etc. The primary focal

Revised Manuscript Received on 14 August, 2019.

Raj Kumar G, - Assistant Professor, Kumaraguru College of Technology, Coimbatore, Tamil Nadu, India.

Balasubramaniyam S, - Associate Professor, Department of Mechanical Engineering, Kumaraguru College of Technology, Coimbatore, Tamil Nadu, India.

Senthil Kumar M, - Assistant Professor (SRG), Kumaraguru College of Technology, Coimbatore, Tamil Nadu, India.

Vijayanandh R, - Assistant Professor, Kumaraguru College of Technology, Coimbatore, Tamil Nadu, India.

Raj Kumar R, - Assistant Professor, Science and Humanities, Kumaraguru College of Technology, Coimbatore, Tamil Nadu, India.

Varun S, - BE-Student, Department of Aeronautical Engineering, Kumaraguru College of Technology, Coimbatore, Tamil Nadu, India. of this research is selection of optimized bumper material by comparing the structural parameters of steel and glass fiber composite bumpers [1].

\section{LITERATURE SURVEY}

R. Ranjithkumar et al., [2], were used Pro/E and SOLID WORKS for conceptual design and impact analysis of bumper, in which the structural parameters such as displacement, strain energy, equivalent strain were considered for comparative study. Glass fiber based composite and ABS Plastic were the materials used for numerical simulation. Nitin S. Motgi et al [3]., this paper provided the procedures involved in the bumper problems in the perspective of numerical methodology, in which $\mathrm{CAD} / \mathrm{CAE}$ tools played the predominant role. V. Kleisnera [4] et al., deals the analyze of composite bumper using the PAM-Crash software. Shell and Ladeveze elements were used in this paper for the purpose of representation of composite original behavior in software. Lande P. R [5]., implemented the Honeycomb sandwich panel in the crash investigation of car and thereby the results were estimated successfully. A. R. MortazaviMoghaddam et al., [6] implemented the Glass Materials in bumper to enhance its properties. CATIA and LS-DYNA tools were used here for conceptual design and structural analysis respectively. From all the previous studies, the following details are obtained which are standard details about bumper are learned, element type, methodology used, boundary conditions, mechanical properties of materials.

\section{COMPOSITE BUMPER}

\subsection{Details of Bumper}

Bumpers used in Automotive Vehicle are not implemented to Vehicle crashworthiness or tenant protection for the period of collisions. Primarily the bumpers implementation concentrated on energy absorption and thereby provides the comfortableness to both passengers as well as vehicle [7]. In order to provide comfortableness, the Bumper and its arrangement have to follow certain standards, which are clearance range and load withstanding capability with respect to speed. Normally, the clearance range between road surface to the bumper is varies from 16 to 20 inches. Also the bumper compulsorily withstand the vehicle speeds of $2 \mathrm{mph}$, $1 \mathrm{mph}$ and $5 \mathrm{mph}$ across its full width, corners and crash on parked environment respectively [8]. 


\subsection{Composite}

Nowadays composites are implemented in all the critical components of automotive vehicle because of its integrated effects. Bumper is one of the critical components in Automatic vehicle, which need to be manufactured with high energy absorbing material therefore Composite has the best alternate for bumper. Integrated effect of composites provides the high impact load withstand capability with low density. In addition to that the composite materials allow rapid response to induced or release stress [9].

\subsubsection{Glass Fiber}

The main focus of the Glass Fiber Reinforced Polymer (GFRP) is to provide high stiffness and strength with low density to the applicable domain. Fundamentally glass fibers are highly resistive to the corrosion and easily fit for moulding process, which lift up glass fibers into mostly used fiber with Epoxy resin for real-time applications [9]. Glass fibers are more comfortable element, which have the capability to provide high strength with low diametrical dimensions. Normally glass fibers are available in different categories based on its property in which C, D, E, R, S are more commonly used categories. In this work, E-glass fibers have been used due to its low delaminating property. The good, which might increase the implementation of this combination in real-time applications [9].

\subsubsection{Epoxy Resin}

The most suitable resin for real time implementation in application is Epoxy because of its lower shrinkage property. Chemical representation of epoxies are low molecular weight organic liquids, which containing the three members. One amount of oxygen and two carbon atoms are assembled in that rings, which formally had known as Epoxide groups. Epoxies are obtained fro the chemical reactions between aromatic amines / phenols with Epichlorohydrin. In order to update the properties of composite laminate, the mixtures such as fillers, mixtures, and hardeners are added with epoxy resins [10]. Epoxy resin is more compatible with glass fibers, which made this combination as mostly implemented pair in the complex real-time applications such as Aerospace, Automobile, Marine, etc. But resins are economically settled in quite high position, which may take into account for research purpose in the perspective of low cost resin production [10].

\subsection{Fabrication of Composite Bumper}

Different types of fabrication processes are available in Composite construction, in which Hand Lay-Up (HLU) is comparatively suitable for all the cases due to this methodology needs a very low thermal environments (25O C to $30 \mathrm{O}$ ) to alleviate with the implementation of low level compressive pressures. The process involved in the HLU is very reliable and simple one, in which fundamental component is fiber and adhesive component is Epoxy resin. HLU is a user friendly one, which permits the user to laminate optimization by locating various types of fibers and adhesive materials [11]. The HLU procedure initiates with arrangement of fiber and then implementation of resin in the appropriate mould in the cascade manner. An external rolling chemistry between Epoxy resin and E-Glass fiber is quite

member is used to permeate the reinforcement with matrix. Each and every construction of laminate has follow the standards, which provides the composite laminate's three dimensional values so the above mentioned arrangement of fibers and matrices with the supports of external members to be continued until the achievement of standard dimensions. In this work, E-glass short listed as reinforcement and Epoxy resin used as matrix and the other supporting components Hardener, Wax are added for strengthen purpose. For successful completion purpose, bumper mould has been used in this work [11].

\section{NUMERICAL SIMULATION OF COMPOSITE BUMPER\& RESULTS}

Numerical simulation methodology is computer based one, in which the attainment of high accuracy in output is completely depends on modeling process of original model, capturing of original model into finite element model and implementation of good boundary conditions. Hence generating process of conceptual design of test specimen is plays a vital role in numerical study.

\subsection{Theoretical Study}

4.1.1 Measurements and Mechanical properties of an Automotive Bumper

From the literature survey the existing geometrical and structural parameters are obtained which are, effective length of the bumper is $0.975 \mathrm{~m}$, length of the bumper is measured as $2.050 \mathrm{~m}$, thickness is $0.002 \mathrm{~m}$, effective breath is $0.070 \mathrm{~m}$ and finally the total breath is $0.170 \mathrm{~m}$. The existing bumper material used in the previous work is steel hence the mechanical properties of steel are density is $7700 \mathrm{~kg} / \mathrm{m} 3$, Poisson ratio is 0.337 and finally young's modulus value is $200 \mathrm{GPa}$. From the known geometrical and mechanical properties, the weight of the steel bumper is calculated which is nothing but $13.70 \mathrm{~kg}$. Previous works also provided the value of tensile strength (450 $\mathrm{MPa})$, which predominantly support the moment estimation of steel bumper with the help of formulae (1), (2) and (3). In order to execute the geometrical parameters of glass fiber based composite the moment has been assumed same for both material cases.

$$
\begin{aligned}
& \frac{\mathrm{M}}{\mathrm{I}}=\frac{\sigma}{\mathrm{y}} \\
& y=\frac{d}{2} \\
& \mathrm{I}=\frac{\mathrm{b}(\mathrm{d})^{3}}{12}
\end{aligned}
$$

Where,

$\mathrm{M}=$ Bending moment (N.m);

$\mathrm{I}=$ Moment of inertia $\left(\mathrm{m}^{4}\right)$;

$\sigma=$ Tensile strength $\left(\mathrm{N} / \mathrm{m}^{2}\right)$;

$\mathrm{d}=$ thickness of the bumper $(\mathrm{m})$;

$\mathrm{b}=$ breadth of bumper $(\mathrm{m})$;

In this work, the test model is comprises of three sections so three moment of inertia need to be estimated $\mathrm{I}_{1}, \mathrm{I}_{2}, \mathrm{I}_{3}$ respectively. 


$$
\begin{aligned}
& I_{1}=\frac{b_{1}\left(d_{1}\right)^{3}}{12} \\
& I_{1}=\frac{(0.055) *(0.002)^{3}}{12}=3.667 \times 10^{-11} \mathrm{~m}^{4}
\end{aligned}
$$

Similarly,

$$
\begin{gathered}
I_{2}=\frac{(0.075) *(0.002)^{3}}{12}=5 \times 10^{-11} \mathrm{~m}^{4} \\
I_{3}=\frac{(0.075) *(0.002)^{3}}{12}=3.667 \times 10^{-11} \mathrm{~m}^{4} \\
I=I_{1}+I_{2}+I_{3}=12.334 \times 10^{-11} \mathrm{~m}^{4} \\
\frac{M}{12.334 \times 10^{-11}}=\frac{450 \times 10^{6}}{0.001} \\
M=55.503 \mathrm{Nm}
\end{gathered}
$$

\subsubsection{Thickness of the Composite Bumper}

In this work, the test model is comprises of three sections so three thickness has to find separately and then consolidation need to take place for attainment of cumulative thickness. Equation (1) is used here for entire calculation.

In order to estimate the thickness of the composite bumper, the equation of (1) can be rewritten as,

$$
\begin{aligned}
& \frac{\mathrm{M}}{\left\{\mathrm{b} *(\mathrm{~d})^{3} / 12\right\}}=\frac{\sigma}{\{\mathrm{d} / 2\}} \\
& \mathrm{d}=\sqrt{\frac{6 \mathrm{M}}{\mathrm{b} * \sigma}}
\end{aligned}
$$

Equation (6) can be rewritten for individual estimation of sectional thickness

Similarly,

$$
\begin{gathered}
d_{1}=\sqrt{\frac{6 \mathrm{M}}{\left(\mathrm{b}_{1}\right) *(\sigma)}} \\
\mathrm{d}_{1}=\sqrt{\frac{6 * 55.503}{(0.055) *\left(450 \times 10^{6}\right)}} \\
d_{1}=3.69 \times 10^{-3} \mathrm{~m}
\end{gathered}
$$

$$
\begin{gathered}
d_{2}=\sqrt{\frac{6 M}{\left(b_{2}\right) *(\sigma)}} \\
d_{2}=\sqrt{\frac{6 * 55.503}{(0.075) *\left(450 \times 10^{6}\right)}} \\
d_{2}=3.1412 \times 10^{-3} \mathrm{~m} \\
d_{3}=\sqrt{\frac{6 \mathrm{M}}{\left(\mathrm{b}_{3}\right) *(\sigma)}} \\
\mathrm{d}_{3}=\sqrt{\frac{6 * 55.503}{(0.075) *\left(450 \times 10^{6}\right)}} \\
\mathrm{d}_{3}=3.1412 \times 10^{-3} \mathrm{~m} \\
\text { (d) }=\frac{\left(3.69 \times 10^{-3}+3.1412 \times 10^{-3}+3.1412 \times 10^{-3}\right)}{3} \\
\left.d=3.324 \mathrm{~mm}_{3}\right)
\end{gathered}
$$

An each layer of E-glass lamina thickness is $0.2 \mathrm{~mm}$, so 16 layers are required for fabricating composite bumper.

\subsubsection{Bumper's Conceptual Design}

The fundamental views of the three dimensional bumper are shown in the figures 1 to 3 . The conceptual design of the bumper is perfectly modeled with the help of CATIA.

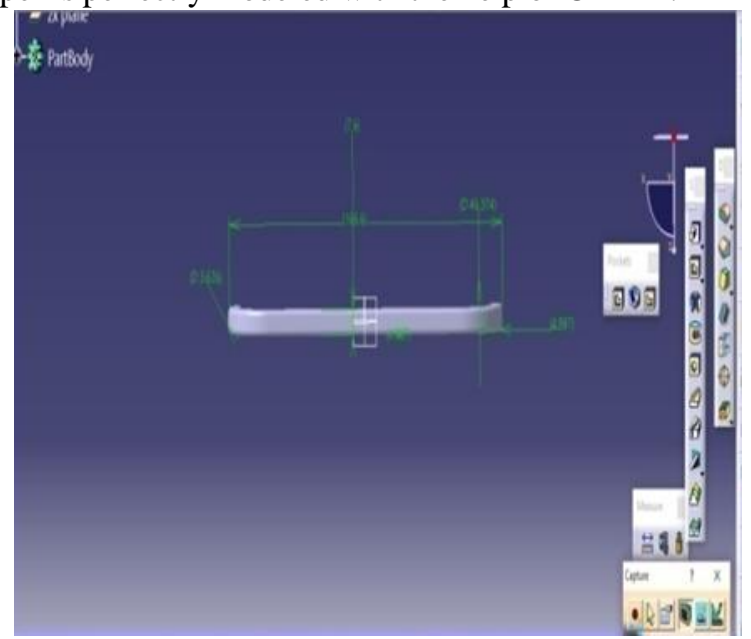

Figure 1 Front view of the Bumper

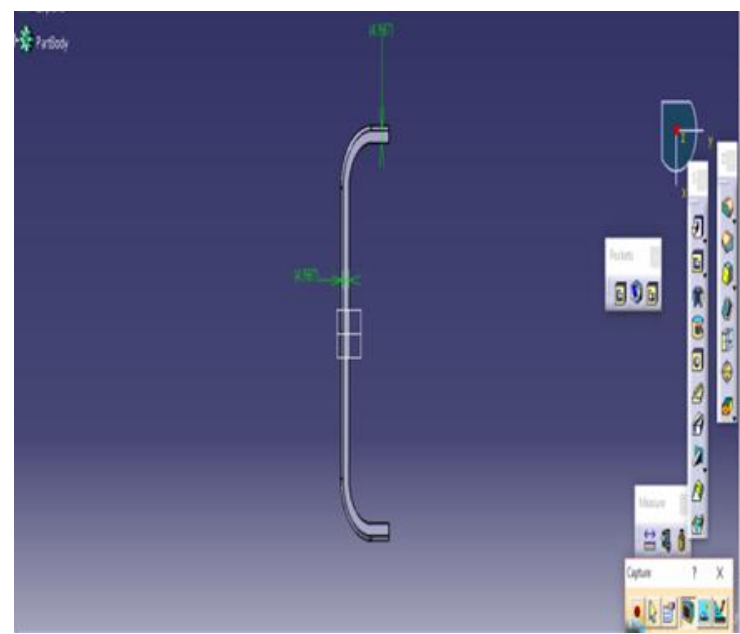

Figure 2 Top view of the Bumper

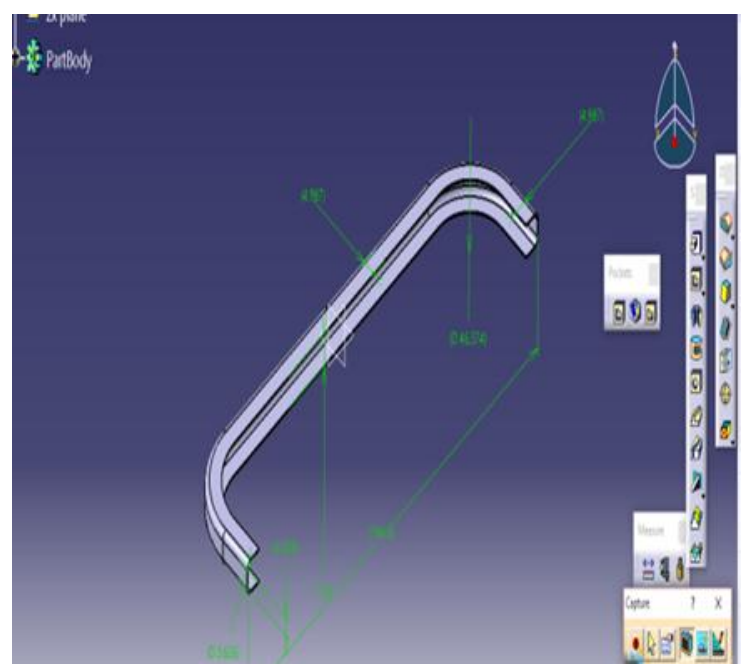

Figure 3 Isometric view of the Bumper

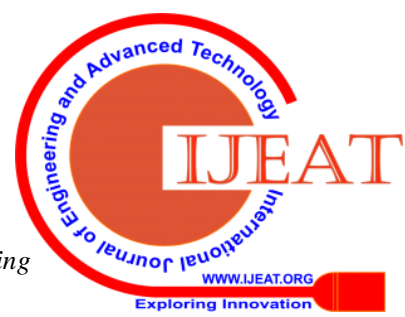




\section{CRASH ANALYSIS ON THE AUTOMOTIVE VEHICLE BUMPER}

\subsection{Numerical Analysis}

The basic concept in Finite Element Analysis (FEA) is that the generation of sub-blocks of entire physical model, in which the whole sub-block must be connected together for result's accuracy. Node and element are components of subblock in which node has the fundamental capability to estimate its displacement when undergoing external load [12]. Structural analysis based numerical modeling is fundamentally depends on three sub-divisional models, which are (1) Components of sub-blocks (node, element) and boundary condition (general properties and support); (2) Mechanical properties of material; and (3) an external/internal force model [12]. In this article ANSYS workbench is used as simulation tool, which used large scale multipurpose finite element different pre-programmed [12]. The advanced Workbench tool have ability to resolve dynamic and static structural problems, transient and steady state thermal based problems, modal and harmonic response problems, linear and non-linear buckling problems, crash investigation problems and static or time varying magnetic analysis. The static-nonlinear analysis is used in this article, which is completed to determine the total displacement, resisting force distribution on the entire car bumper [12].

\subsubsection{Mesh of Car Bumper}

The discretized model of the bumper is shown in the figure 4 , in which the fine uniform mesh has been generated with the help of proximity and curvature set-up. The details about the sub components of meshed model is checked and listed in table 1.

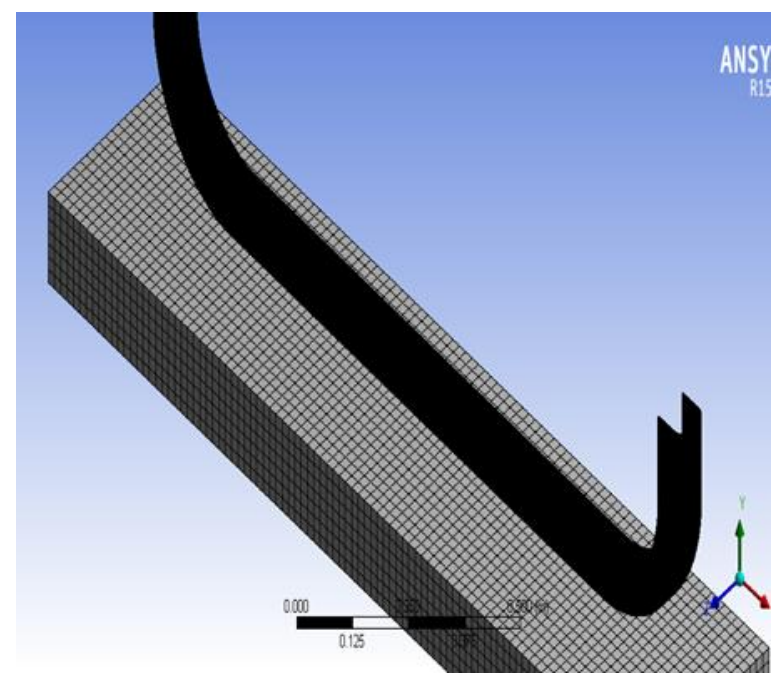

Figure 4.Mesh of car bumper

Table 1.Mesh details

\begin{tabular}{|c|c|}
\hline Mesh Type & Triangle surface mesh (fine mesh) \\
\hline Nodes & 6792786 \\
\hline Elements & 5641120 \\
\hline Mesh quality & 0.78 \\
\hline
\end{tabular}

\subsubsection{Boundary Condition}

Supports and their reactions provide major contribution in the numerical simulation calculation. In this work, fixed support is applied in the both the ends of the bumper. The bumper is fixed at the tolerance value of $547.88 \mathrm{~mm}$ from centre of the vehicle's front region. Table 2 provides the data of mechanical properties of Steel and GFRP composite, which are drastically, contributes their involvement in the representation process in numerical simulation.

Table 2.Description for Steel and Composite Bumper

\begin{tabular}{|c|c|c|}
\hline Description & Steel & Composite \\
\hline Element type & Solid186 & Solid191 \\
\hline Pres sure Load (N/mm $)$ & 0.13 & 0.13 \\
\hline $\begin{array}{c}\text { Young's } \\
\text { modulus(N/mm }\end{array}$ & $2 \times 10^{2}$ & $78 \times 10^{2}$ \\
\hline Poisson's ratio & 0.3 & 0.27 \\
\hline
\end{tabular}

\subsubsection{Force Acting On the Bumper $(F)$}

In general, external loads such as aerodynamic load, hydrodynamic loads are intended to acting on the entire surface of the object instead of single point interaction so these type of loads are comes under UDL (Uniformly Distributed Load) category. In this work, the external collision impact is acting in the entire region of the bumper therefore the impact load is considered as UDL category.

The calculation of UDL is estimated with the help of pressure formula (7),

$$
\begin{aligned}
& \mathrm{P}=\frac{\mathrm{F}}{\mathrm{A}} \\
& \mathrm{F}=\mathrm{m} * \mathrm{a} \\
& \mathrm{a}=\frac{(\mathrm{u}-\mathrm{v})}{\mathrm{t}}
\end{aligned}
$$

Where,

$\mathrm{P}$ - External impact load in the form UDL mode

$\mathrm{F}$ - Force applied on the bumper in Newton

A - Cross Sectional area (perpendicular to collision region)

$\mathrm{m}=$ Bumper's mass $(1554 \mathrm{~kg})$

$\mathrm{a}=$ acceleration due to gravity $(\mathrm{m} / \mathrm{sec} 2)$

$\mathrm{v}=$ Final velocity after deformation $(\mathrm{m} / \mathrm{sec})$;

$\mathrm{u}=$ Initial velocity before deformation $(\mathrm{m} / \mathrm{sec})$;

Substitute all the known values $(\mathrm{u}=2.08 \mathrm{~m} / \mathrm{s} ; \mathrm{v}=0 \mathrm{~m} / \mathrm{s} ; \mathrm{t}$ $=0.1 \mathrm{~s})$ in the equations (7), (8) and (9). The output parameters are

$$
\begin{aligned}
& a=\frac{(2.08-0)}{0.1}=20.08\left(\mathrm{~m} / \mathrm{s}^{2}\right) \\
& \mathrm{F}=1554 * 20.08=31204.32 \mathrm{~N}
\end{aligned}
$$

From the previous work, the value of the cross sectional area is determined as $154125 \mathrm{~mm}^{2}(2055 \times 75)$. Hence,

$$
\mathrm{P}=\frac{31204.32}{154125}=0.2025\left(\mathrm{~N} / \mathrm{mm}^{2}\right)
$$




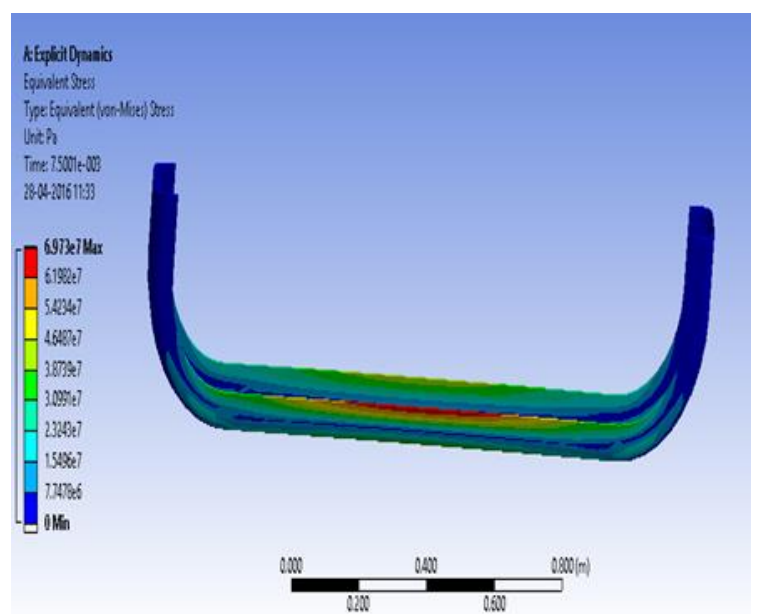

\subsubsection{Stress Distribution Results}

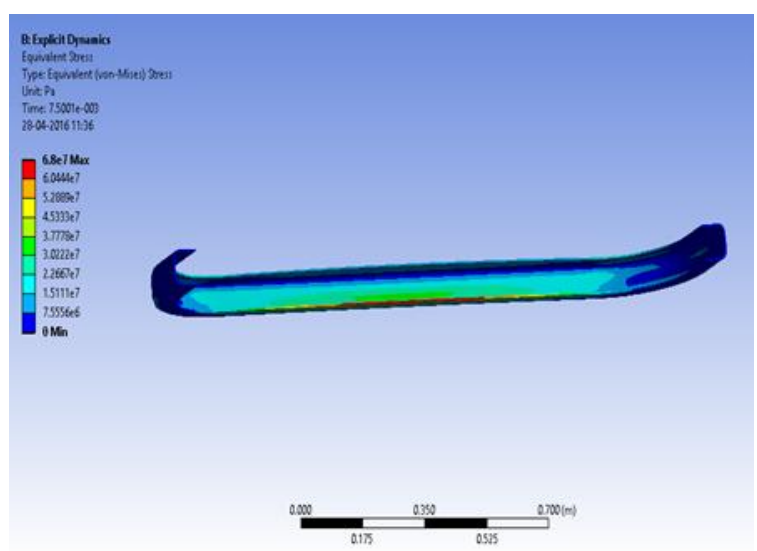

Figure 5.Stress Distribution for steel Bumper

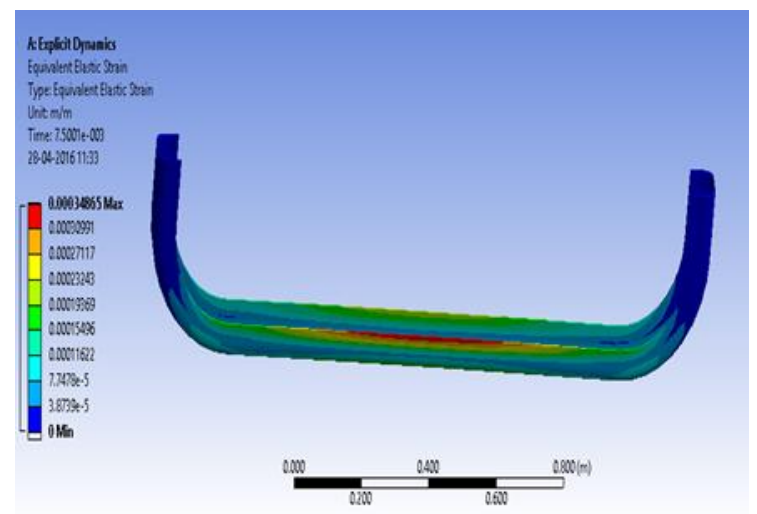

Figure 6.Stress Distribution of Composite Bumper

The stress variations of Steel bumper and GFRP bumper are revealed in the figure 5 and 6 respectively. For same boundary conditions, the maximum stress occurred in the steel bumper compared with composite bumper therefore composite have the capability of load withstand at the collision environment.

\subsubsection{Strain variation Results}

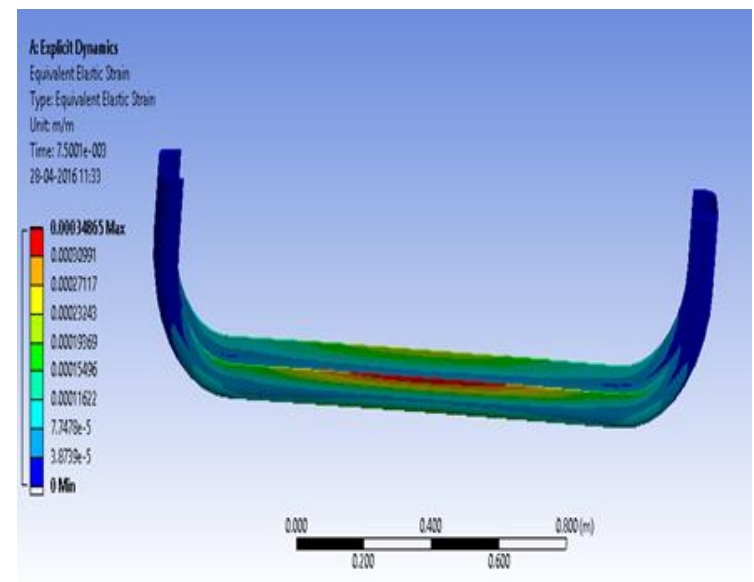

Figure 7.Strain Distribution of steel Bumper

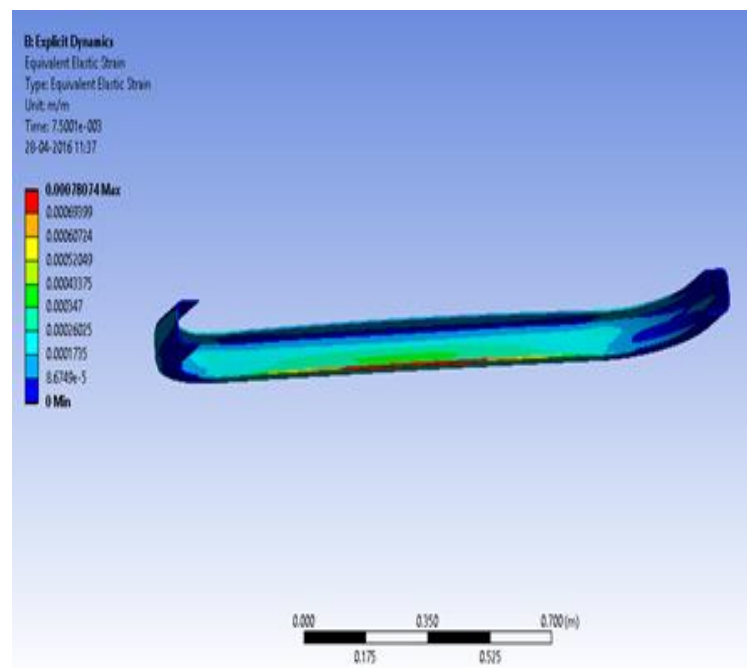

Figure 8.Strain Distribution of composite Bumper

Figure 7 and 8 shows the variations of strain on Steel and GFRP bumpers respectively.

\subsubsection{Total Deformation Results}

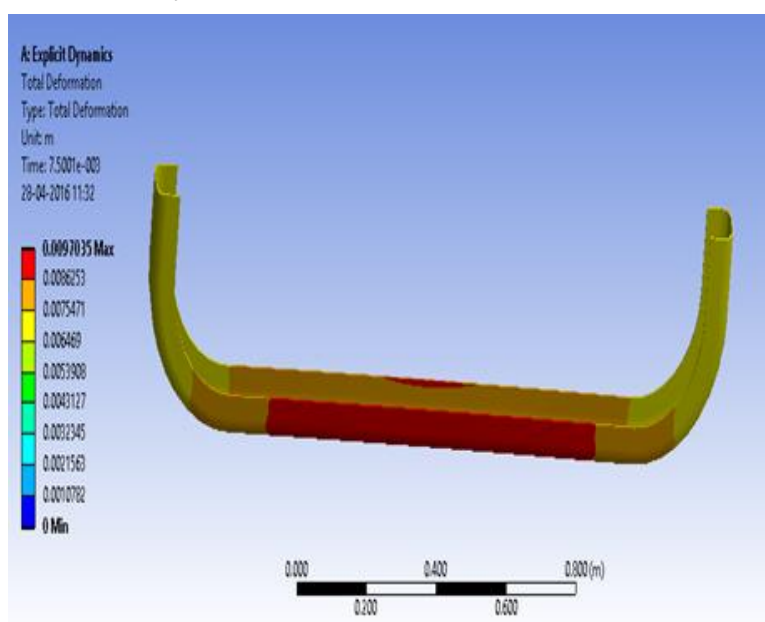

Figure 9.Total deformation of steel Bumper

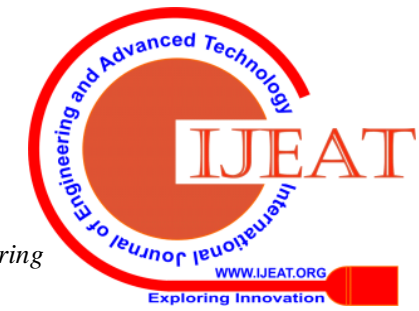




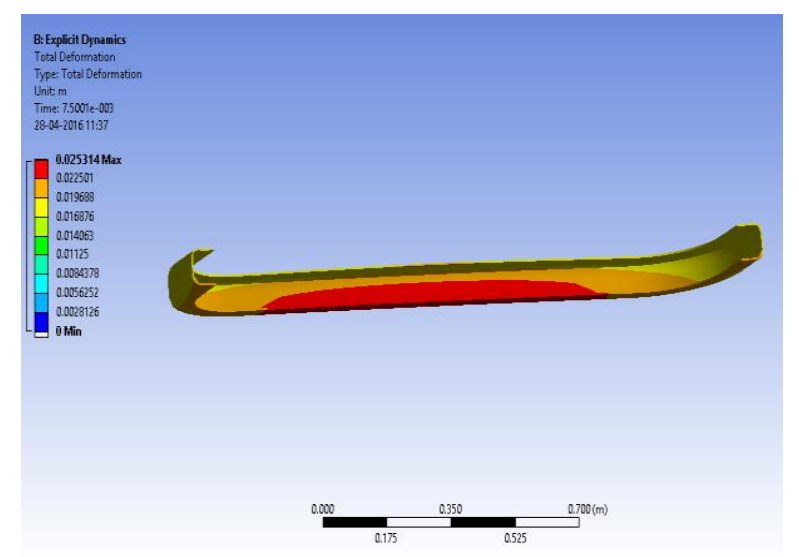

Figure 10.Total deformation of Composite Bumper

The displaced structures are revealed in the figures 9 and 10 , In which figure 9 corresponds to steel bumper and figure 10 belongs to GFRP bumper. From the results it has been understood that steel bumper have more stiffness than composite bumper. The structural results are checked carefully and then the data are listed in table 3.

\subsubsection{Comparison}

Table 3.Result of FEA

\begin{tabular}{|c|c|c|}
\hline Description & Steel bumper & Composite bumper \\
\hline Max stres5 $(\mathrm{Pa})$ & $6.973 \times 10^{7}$ & $6.8 \times 10^{7}$ \\
\hline $\begin{array}{c}\text { Total Deformation } \\
(\mathrm{m})\end{array}$ & 0.0097035 & 0.025314 \\
\hline
\end{tabular}

\section{CONCLUSIONS}

The standard formulae are contributed towards the attainment of conceptual design of bumper. Literature survey about bumpers have provided the details of mechanical properties of short listed materials and then details are supported for successful completion of numerical simulation. From the previous works, it is understood that composite bumper is $53.8 \%$ lesser than steel bumper with high load withstanding capability and also in the cost perspective composite bumper is $80 \%$ less than steel bumper. The conceptual design and numerical simulation of bumper have been successfully completed with the help of CATIA and ANSYS Workbench respectively, in which $64 \%$ of factor of safety is increased in Glass fiber based composite compared with Steel. Finally it is understood that, Glass fiber based composite is more comfortable for automotives bumper.

\section{REFERENCES}

1. Vijayanandh R et al., Numerical Study on Structural Health Monitoring for Unmanned Aerial Vehicle, Journal of Advanced Research in Dynamical and Control Systems, Vol. 9. Sp- 6 / 2017, pp 1937 - 1958.

2. R. Ranjithkumar, J.P. Ramesh, Modelling And Analysis of a Car Bumper Using Various Materials by FEA Software, Journal of Chemical and Pharmaceutical Sciences ISSN: 0974-2115, Special Issue 9: April 2015, pp 294 - 298.

3. Nitin S. Motgi, S. B. Naik, P.R.Kulkarni, Impact Analysis of Front Bumper, International Journal of Engineering Trends and Technology (IJETT) - Volume 6 Number 5- Dec 2013, pp 287 - 291.
4. V. Kleisner et al., Analysis of composite car bumper reinforcement, Applied and Computational Mechanics 3 (2009), pp. 287-296.

5. Lande P.R, Patil R.V., Analysis of Bumper Beam in Frontal collision, International Journal of Innovative Research in Science, Engineering and Technology, Vol. 4, Issue 5, May 2015, pp 2807 - 2810.

6. A.R. Mortazavi Moghaddam, M. T. Ahmadian, Design and Analysis of an Automobile Bumper with the Capacity of Energy Release Using GMT Materials, World Academy of Science, International Journal of Mechanical and Mechatronics Engineering, Vol:5, No:4, 2011, pp 865 - 872.

7. Vijayanandh R. et al., Material Optimization of High Speed Micro Aerial Vehicle using FSI Simulation, Procedia Computer Science, Volume Number 133, 2018, pp 2-9.

8. Falaichen, Bert Juttler, Geometric Modelling \& Processing, Journal on CAD, 42(1), 1- 15.

9. Vijayanandh R. et al., Vibrational fatigue analysis of NACA 63215 small horizontal axis wind turbine blade, Materials Today: Proceedings, Volume 5, Issue 2, Part 2, 2018 , $\mathrm{pp}$ $6665-6674$ https://doi.org/10.1016/j.matpr.2017.11.323

10. Raj Kumar G et al., The Design Optimization of the Circular Piezoelectric Bimorph Actuators Using FEA, International Journal of Mechanical and Production Engineering Research and Development, ISSN(P): 22496890, Vol. 8, Special Issue 7, Oct 2018, 410-422.

11. Kaw, Autar K, "Mechanics of composite material", CRC Press, New York, 1997.

12. Vijayanandh R et al., Conceptual design and structural analysis of integrated composite Micro Aerial Vehicle, Journal of Advanced Research in Dynamical and Control Systems, Vol. 9. Sp- 14 / 2017, pp 857 - 881. 